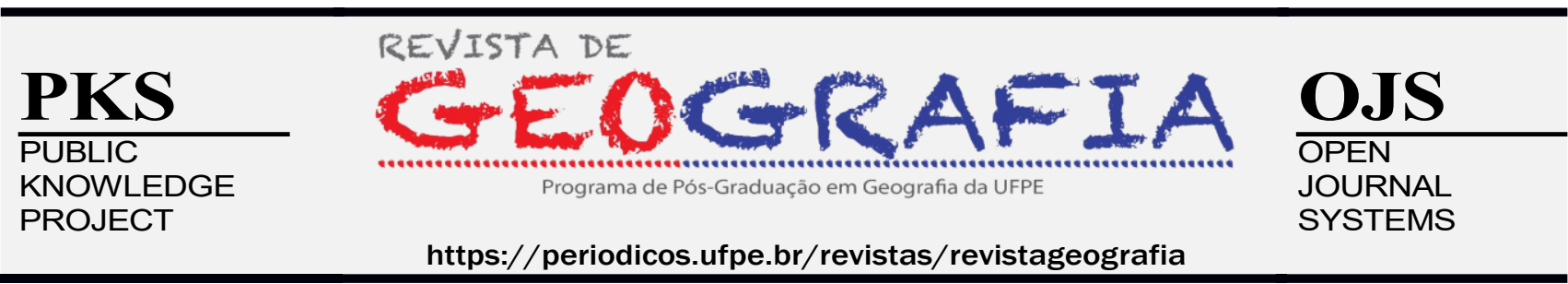

\title{
A ESTRANGEIRIZAÇÃO DA TERRA NA PARAÍBA: TERRITORIALIDADES, AGENTES E DINÂMICAS
}

\author{
Lorena Iza Pereira ${ }^{1}$
}

${ }^{1}$ Doutora em Geografia pela Universidade Estadual Paulista (UNESP), campus de Presidente Prudente. Pós-doutoranda pela Universidade Federal da Paraiba (UFPB) Pesquisadora do Núcleo de Estudos, Pesquisas e Projetos de Reforma Agrária (NERA), Presidenta da Diretoria Executiva Nacional da Associação dos Geógrafos Brasileiros (AGB) (20202022), E-mail: lorena.izap@gmail.com, Orcid: http://orcid.org/0000-0002-2352-1760

Artigo recebido em 23/05/2021 e aceito em 18/09/2021

\begin{abstract}
RESUMO
A estrangeirização da terra corresponde a um processo de controle do território (a partir das múltiplas dimensões e escalas) por agentes estrangeiros com o objetivo de garantir a acumulação do capital. Historicamente a estrangeirização no Brasil tem sido materializada mediante diferentes arranjos, porém com o mesmo objetivo. No século XXI, diante da convergência de múltiplas crises e mudanças geopolíticas globais, as dinâmicas da estrangeirização são renovadas. A região Nordeste, embora seja menos expressiva em termos de hectares sob propriedade de estrangeiros (segundo dados oficiais), apresenta uma complexidade ímpar, especialmente por se tratar de uma área de fronteira da apropriação de recurso e, a Paraíba, segue o mesmo sentido. O objetivo deste artigo é evidenciar como a estrangeirização da terra se materializa na Paraíba no século XXI. A partir de metodologias como levantamento e sistematização de dados e pesquisa documental, é possível concluir que o capital estrangeiro por meio da compra, arrendamento e concessões, tem controlado a terra para acessar diferentes recursos, impactando diferentes modos de vida do campo paraibano.
\end{abstract}

Palavras-chave: Controle do território; Região Nordeste; Energia renovável; Agronegócio; Mineração.

\section{THE FOREIGNIZATION OF LAND IN PARAÍBA STATE: TERRITORIALITIES, AGENTS AND DYNAMICS}

\begin{abstract}
The foreignization of the land corresponds to a process of control of the territory (from multiple dimensions and scales) by foreign agents in order to guarantee the accumulation of capital. Historically, foreignization in Brazil has been materialized through different arrangements, but with the same objective. In the 21 st century, in the face of the convergence of multiple crises and global geopolitical changes, the dynamics of foreignization are renewed. The Northeast region, although less expressive in terms of hectares under the ownership of foreigners (according to official data), presents a unique complexity, especially because it is a frontier area for resource appropriation and, state of Paraíba, follows the same direction. The purpose of this article is to show how the foreignization of the land materializes in Paraíba in the 21st century. Based on methodologies such as data collection and systematization and documentary research, it is possible to conclude
\end{abstract}


that foreign capital through the purchase, leasing and concessions, has controlled the land to access different resources, impacting different ways of life in the Paraíba countryside.

Keywords: Territory control. Northeast region. Renewable energy. Agribusiness. Mining.

\title{
LA EXTRANJERIZACIÓN DE TIERRAS EN PARAÍBA: TERRITORIALIDADES, AGENTES Y DINÁMICAS
}

\begin{abstract}
RESUMEN
La extranjerización de la tierra corresponde a un proceso de control del territorio (desde múltiples dimensiones y escalas) por parte de agentes extranjeros con el fin de garantizar la acumulación de capital. Históricamente, la extranjerización en Brasil se ha materializado a través de distintos arreglos, pero con el mismo objetivo. En el siglo XXI, ante la convergencia de múltiples crisis y cambios geopolíticos globales, se renuevan las dinámicas de extranjerización. La región Nordeste, aunque menos expresiva en cuanto a hectáreas de propiedad extranjera (según datos oficiales), presenta una complejidad única, sobre todo porque es una zona de frontera para la apropiación de recursos y, Paraíba, sigue la misma dirección. El propósito de este artículo es mostrar cómo se materializa la extranjerización de la tierra en Paraíba en el siglo XXI. Con base en metodologías de recolección y sistematización de datos e investigación documental, es posible concluir que el capital extranjero a través de la compra, arrendamiento y concesiones, ha controlado la tierra para acceder a diferentes recursos, generando impactos en diferentes formas de vida del campo paraibano.
\end{abstract}

Palabras-clave: Control territorial. Región nordeste. Energía renovable. Agronegocio. Minería.

\section{INTRODUÇÃO}

Como toda pesquisa científica, este artigo é oriundo de inquietações presentes ao longo de uma década de estudos sobre a estrangeirização da terra no Brasil. A estrangeirização emerge como tema de investigações acadêmicas a partir de 2009, momento o qual se observa o aumento de transações de terras em larga escala, a conhecida corrida mundial por terras (no inglês tratado como land rush e land grabbing) (EDELMAN, OYA e BORRAS JR., 2013). O Brasil, inclusive, se tornou objeto de pesquisas em âmbito nacional e internacional, justamente pela complexidade que o processo assume no país.

Desde então, um volume considerável de pesquisas tem sido conduzido nas mais diferentes áreas do conhecimento, especialmente na Geografia (PEREIRA, 2018) e nas Relações Internacionais (SOYER e BARBOSA, 2018). Contudo, mesmo diante desta posição privilegiada, a abordagem da estrangeirização tem apresentado algumas tendências e, de certo modo, vícios de tratamento. Isso significa que algumas questões são favorecidas e outras, tão importantes quanto, são frequentemente deixadas de lado nas análises.

Um exemplo representativo é a quantidade de pesquisas centradas na estrangeirização para fins agrícolas, sobretudo na cana-de-açúcar e, em menor proporção, na soja e silvicultura. Em termos 
de escala de análise, a maior parte das investigações possuem como foco o estado de São Paulo (particularmente devido a incidência da cana-de-açúcar), a Amazônia e a região conhecida como MATOPIBA $^{1}$, considerada como a última fronteira agrícola em área de Cerrado e que concentra maior presença de capital estrangeiro em investimentos em terras (FREDERICO e ALMEIDA, 2019).

É lógico que a ciência está em movimento e aos poucos é possível observar mudanças nas abordagens, novos temas de pesquisa emergem de acordo com a realidade. Todavia, o foco da análise da estrangeirização no Brasil ofusca outras possibilidades tão expressivas quanto as acima citadas. Justamente por isso, este artigo tem como foco a estrangeirização da terra no estado da Paraíba (Nordeste), especialmente a partir da multiplicidade de usos do território, isto é, considerando a estrangeirização para além da produção agrícola e inserindo a mineração e a produção de energia alternativa como territorialidades (usos do território) da mesma. Desta forma, o objetivo deste artigo é evidenciar como a estrangeirização da terra se materializa na Paraíba no século XXI.

A estrangeirização da terra é entendida aqui como um processo de controle do território por agentes estrangeiros em múltiplas escalas e dimensões, o que a coloca como parte de um processo mais amplo, que é o land grabbing. Assim, a estrangeirização da terra não é uma tradução de land grabbing e sim um elemento deste. Mais do que um poder diretivo e repressor sobre o território (MACHADO, 1997), o controle do território envolve a dimensão material e imaterial, nem sempre necessitando da propriedade de um determinado "pedaço" de terra. Além da terra, o é o controle dos recursos naturais (águas, biodiversidade, fertilidade do solo, minérios), das territorialidades, dos insumos agrícolas, das políticas públicas, das relações sociais, do Estado, da mídia e dos discursos.

O controle do território é um processo solidário (SASSEN, 2016). São empresas privadas (limitadas e sociedades anônimas), empresas estatais, fundos de investimentos (soberanos, private equity, hedge), instituições multilaterais, bancos (públicos e privados) que levam a cabo a estrangeirização. Porém, para isso são necessários outros atores, como as empresas nacionais, os proprietários e grileiros locais, os funcionários cartoriais (FREDERICO e ALMEIDA, 2019) e o próprio Estado. Assim, é um processo que está entremeado por relações de poder entre diferentes agentes e que atuam em diversas escalas, formando uma rede (BORRAS ET AL., 2020). Embora a diversidade de envolvidos seja expressiva, o objetivo do controle do território é garantir a acumulação do capital. É justamente neste sentido amplo que a estrangeirização é compreendida.

\footnotetext{
${ }^{1}$ Região composta por 337 municípios dos estados do Maranhão (135), Tocantins (139), Piauí (33) e Bahia (30).
} 
A estrangeirização não envolve apenas as transações de terras ocorridas via compra, mas arrendamentos, concessões, contratos de parcerias, direitos do uso de superfície, aquisição de empresas (especialmente com falência decretada), joint-ventures, compras de ações no caso de empresas com capital aberto na bolsa de valores. Desta forma, não é necessária a propriedade da terra para que a estrangeirização seja materializada, há formas mais sutis de controle. Segundo McKay (2017, p. 50) "captures the new forms and mechanisms of resource control and value appropriation (or extraction) in (agro) extractive sectors through an analysis of access rather than property or concessional rights".

Ao remontar a história da invasão e colonização pelos portugueses e todo o processo que desde então se sucede, é possível afirmar que a estrangeirização é histórica. O sentido da formação do Brasil, segundo Prado Jr. (2011) foi o de justamente atingir um objetivo exterior, produzir culturas (açúcar, tabaco, algodão) e explorar recursos (a terra, o pau-brasil, mais tardar o ouro e diamante) para o comércio exterior, onde os bancos europeus especulavam, realizavam negócios e o trabalho escravo era necessário para essa situação. Assim, o trabalho escravo, o latifúndio, a monocultura, a mineração e o extrativismo se constituem como fundamentais porque representam a base em que se sustenta a vida na colônia e constituem a razão de sua existência. A estrangeirização tem a sua base iniciada com a colonização.

Tanto a formação do Brasil, quanto a estrangeirização da terra, seguem as dinâmicas dos ciclos espaciais de acumulação, que são entendidos como "movimento unitário-integrativo de reprodução da totalidade da diversidade de áreas e setores de atividades identificada com a forma de capital dominante de cada contexto" (MOREIRA, 2018, p. 24). Os ciclos espaciais de acumulação que permearam a formação e a estrangeirização no Brasil pautados na cana-de-açúcar, na mineração, no café, na cadeia de soja/óleos/carnes (MOREIRA, 2005 e 2018). Hoje o ciclo de acumulação de capital está pautado na produção de commodities flexíveis ${ }^{2}$ e na financeirização, não apenas da agricultura, mas sim de todas as esferas da vida. Desta forma, o que se altera ao longo do tempo são os arranjos espaciais (MOREIRA, 2020), os elementos fundantes que o compõem são os mesmos.

No século XXI um dos fatos que tem ditado a estrangeirização é que a "dinâmica expansiva do agronegócio depende da disponibilização permanente de novos estoques de terras"

\footnotetext{
${ }^{2}$ Conhecidos como Flex Crops. São commodities que apresentam múltiplos usos, sendo destinadas para a produção de alimentos, ração animal, fibras e energia - os 4Fs - Food, Feed, Fiber e Fuel. Antes mesmo de se constituírem como commodities, essas culturas já apresentavam, de certa forma, um uso flexível por comunidades tradicionais ao redor do mundo. Assim, não são apenas os novos usos de culturas, mas as novas economias em torno destes usos (REYES e SANDWELL, 2018).
} 
(ALENTEJANO, 2020, p. 378) seja para a produção agrícola ou para a exploração da natureza. É justamente a dita corrida mundial por terras que culmina na despossessão e subordinação de camponeses, indígenas, quilombolas e demais comunidades tradicionais. É devido a esta necessidade que são cada vez mais frequentes a criação de mecanismos que "liberem" terras para serem incorporadas pelo capital, como projetos de regularização fundiária e de titulação massiva de terras (SAUER, LEITE e TUBINO, 2020). Além de terras, são necessários novos mercados para a expansão do capital e, é assim que a natureza passa a ser valorizada como um ativo de reposição (FAIRHEAD, LEACH e SCOONES, 2012), exemplos de mecanismos são os Green Bonds ${ }^{3}$ e Redução de Emissão do Desmatamento e Degradação Florestal (REDD+).

É justamente entendendo toda a dimensão histórica do processo da estrangeirização, o seu novo arranjo no século XXI e sua complexidade caracterizada pelas múltiplas territorialidades, que o artigo está estruturado em três partes. Primeiramente é abordada a estrangeirização da terra no Brasil. A segunda seção traz a discussão com ênfase na região Nordeste, elencando, especialmente, os arranjos que o processo assume na atualidade. Por fim, é debatida a estrangeirização do território paraibano, focando nas multiterritorialidades do processo no século XXI.

Para atingir o objetivo foram utilizadas metodologias quantitativas, com o levantamento de dados em diferentes órgãos públicos e de organizações não governamentais. Para a produção agrícola e silvicultura foram utilizados de dados do Instituto Brasileiro de Geografia e Estatística (IBGE); os dados acerca das energias alternativas (eólica e fotovoltaica) são do Sistema de Informações de Geração da ANEEL (SIGA), por fim, as informações sobre a estrangeirização da terra são do Sistema Nacional de Cadastro Rural (SNRC) e do portal Land Matrix ${ }^{4}$.

De antemão é necessário enfatizar as dificuldades na obtenção de dados sobre as transações de terras, especialmente quando estas envolvem uma gama de agentes estrangeiros. Os empecilhos são múltiplos, desde a falta de transparência nas negociações até as diversas formas de acesso e controle que não exigem obrigatoriamente a propriedade da terra, como os arrendamentos, contratos de parceria, concessões e direitos do uso de superfície. Assim, é importante considerar que os dados sobre a estrangeirização tendem a ser subestimados.

É justamente entendendo toda a dimensão histórica do processo da estrangeirização, o seu novo arranjo no século XXI e sua complexidade caracterizada pelas múltiplas territorialidades, que o

\footnotetext{
${ }^{3}$ Conhecidos como Títulos Verdes.

${ }^{4}$ Maiores informações disponíveis em: https://landmatrix.org/. Acesso em: 14 mai. 2021.
} 
artigo está estruturado em três partes. Primeiramente é abordada a estrangeirização da terra no Brasil. A segunda seção traz a discussão com ênfase na região Nordeste, elencando, especialmente, os arranjos que o processo assume na atualidade. Por fim, é debatida a estrangeirização do território paraibano, focando nas multiterritorialidades do processo no século XXI.

\section{APONTAMENTOS SOBRE A ESTRANGEIRIZAÇÃO DA TERRA NO BRASIL}

A estrangeirização tem se materializado no Brasil desde 1500. Porém começa a assumir novas dinâmicas depois da promulgação da Lei de Terras de 1850, justamente pela transformação da terra em mercadoria. No final do século XIX e início do século XX a estrangeirização foi marcada pela presença de capitais ingleses dedicados, sobretudo, a exploração de madeira e construção de infraestruturas de integração, como as ferrovias e que acessavam à terra por meio de concessões e doações. Um exemplo clássico é o caso da Guerra do Contestado (1912-1916), episódio no qual camponeses foram desterritorializados para que a empresa estadunidense Brazil Railway Company (MOREIRA, 2019) se instalasse na região conhecida como Contestado, entre os estados do Paraná e Santa Catarina, para a construção da Ferrovia São Paulo - Rio Grande. Foram doados 9 km de cada margem do que viria a ser a rodovia pelo Estado (MARTINS, 1995).

Na segunda metade do século XX o alvo do capital estrangeiro foi a Amazônia, particularmente devido a vocação mineral e a biodiversidade na região. Os órgãos responsáveis pela realização da reforma agrária - Instituto Brasileiro de Reforma Agrária (IBRA) e Instituto Nacional de Desenvolvimento Agrário (INDA) - ambos criados pelo governo ditatorial foram agentes ativos na promoção da grilagem de terras e estrangeirização (OLIVEIRA, 2007). Diante da expressividade do caso, foi realizada em 1968 a Comissão Parlamentar de Inquérito (CPI), que resultou no Relatório Veloso.

Tal relatório colocou em cena dados expressivos e dinâmicas de corrupção envolvendo a estrangeirização da terra. Segundo o documento, mais de 20.000.000 hectares estavam em posse de estrangeiros no Brasil, sendo 15.000.000 apenas na Amazônia (OLIVEIRA, 1988). O escândalo maior foi que funcionários de órgãos públicos estavam diretamente envolvidos no processo, atuando como agentes imobiliários. Foi neste contexto que foram estabelecidos os primeiros marcos regulatórios com o objetivo de controlar a apropriação de terras por estrangeiros. Entre 1968 e 1970 houveram diferentes tentativas institucionais de restringir a estrangeirização, mas apenas em outubro de 1971 é posta a Lei n. 5.709, em vigência até hoje. A Lei em questão estabelece destinatários (a 
quem a legislação se aplica), limites de extensão (incluindo a soma total), formalidades e autorizações especiais (em áreas de interesse nacional).

Em muitos casos, os marcos jurídicos não estão alheios a conjuntura política e econômica. Por isso, a partir da década de 1990 foram removidos obstáculos legais à livre circulação do capital internacional em consonância com o avanço do neoliberalismo na América Latina. Em 1994 foi adotado o Parecer GQ-22 (1994) da Advocacia-Geral da União (AGU), que reconheceu o conceito de empresa brasileira sem qualquer restrição (CASTRO e SAUER, 2017). Em agosto de 1995 outra alteração ocorre desta vez por meio da Emenda Constitucional n. 06, revogando o Artigo 171 da Constituição Federal de 1988 e, "a partir de então, para ser brasileira, bastaria que a pessoa jurídica fosse constituída sob leis brasileiras, com sede e administração no país" (CASTRO e SAUER, 2017, p. 44). Em 1998 o então Parecer GQ-22 foi revisto e encaminhou-se o Parecer GQ-181, “em linhas gerais, permaneceu o entendimento pela revogação do $\S 1^{\circ}$ do art. $1^{\circ}$ da Lei n. 5.709/1971 apesar da revogação do art. 171 da Constituição de 1988” (CASTRO e SAUER, 2017, p. 45).

A conjuntura mundial dos primeiros anos do século XXI, marcada pelo consenso das commodities (SVAMPA, 2019) que, por sua vez, foi propiciado pelo megaciclo/boom das comodities, possibilitou a intensificação da corrida mundial por terras e, consequentemente, aumentou a estrangeirização. Em 2007/2008 o cenário começa a ser alterado e emerge o que é tratado pela academia como convergência de múltiplas crises (EDELMAN, OYA e BORRAS JR., 2013), isto é, uma simultaneidade entre as crises financeira, alimentar, ambiental/climática e energética. A lógica é que diante deste contexto de crises - ou narrativas de crise - uma alterativa é a expansão do capital rumo a novos territórios e mercados.

O Brasil, que historicamente se constituiu como alvo de capitais estrangeiros, foi, mais uma vez, objeto de interesse destes agentes, especialmente em decorrência do preço e da qualidade da terra e das facilidades jurídicas (fundiária, ambiental e trabalhista). Em 2010, diante deste contexto, houve uma nova mudança jurídica. Foi promulgado em 19 de agosto de 2010 o Parecer LA-01 da AGU, que revogou os Pareceres GQ-22 (1994) e GQ-181 (1998) e restringiu a aquisição de terras por estrangeiros no ápice do processo no Brasil. O governo foi alvo de críticas sob a narrativa de que a medida estaria restringindo investimentos. Todavia, mesmo com um marco regulatório bem definido, a aquisição de terras por agentes de outras nacionalidades continuou (e continua) ocorrendo por meio do "jeitinho brasileiro" (PEREIRA, 2018). 
Outra questão que merece destaque é a forma como a aquisição de terras por estrangeiros é controlada pelo Estado. No Brasil o órgão responsável for isso é o INCRA por meio do SNCR. Contudo, mesmo necessitando de autorização especial nas transações acima de três módulos fiscais, os dados encaminhados ao INCRA são autodeclarados, o que significa que o comprador deve declarar a propriedade adquirida. Junto a isso, é somada a pequena a fiscalização em torno das terras declarada ou não, resultado dos recorrentes cortes orçamentários de órgãos de inspeção. É importante pontuar que o Brasil é um país de dimensões continentais, o que potencialmente dificulta a fiscalização em um contexto de desmonte.

Tal situação reverbera em diferentes problemas, inclusive relacionados à segurança nacional, uma vez que o "Brasil não sabe a localização e o tamanho das terras controladas por multinacionais" (CORREIO BRAZILIENSE, 21 jun. 2010). Os dados presentes no SNCR não refletem a atualidade do processo, primeiramente porque há transações não declaradas; secundariamente, não há uma verificação daquilo que foi autodeclarado e, por fim, considera apenas as transações ocorridas via compra de terras. Segundo dados do SNCR atualizados em 01 de maio de 2021, existem 8.064.655 imóveis rurais declarados, totalizando 1.009.977.365 hectares, com a seguinte distribuição (Tabela $01)$.

Tabela 01: Brasil - Tipologias dos imóveis rurais segundo a nacionalidade (2021).

\begin{tabular}{c|c|c}
\hline Tipologia & Propriedade & Hectares \\
\hline Brasileiros & 2.794 .430 & 448.133 .224 \\
\hline Estrangeiros & 27.182 & $3.729 .388,00$ \\
\hline Outros* $^{*}$ & 4.919 & 342.383 \\
\hline Sem informação** & 5.238 .124 & 557.764 .776 \\
\hline Total & $\mathbf{8 . 0 6 4 . 6 5 5}$ & $\mathbf{1 . 0 0 9 . 9 6 9 . 7 7 1}$ \\
\hline
\end{tabular}

* Na coluna nacionalidade consta a descrição "outros".

** Não costa informações na coluna nacionalidade.

Fonte: SNCR (01 mai. 2021). Org.: Autora (2021).

De antemão, apenas pela expressividade de imóveis declarados sem informações de nacionalidade, é possível constatar a fragilidade do cadastro no sentido de que o mesmo não representa a realidade do processo. É importante mencionar que no campo "nacionalidade" do SNCR, há muitas propriedades sem informação e muitas com a descrição "outros", o que dificulta a investigação. Analisando apenas as terras registradas em nome de estrangeiros, a unidade da federação “campeã” em termos de extensão territorial é Mato Grosso, com 828.985,84 hectares 
estrangeirizados (22,22\%), seguida de Mato Grosso do Sul, que concentra 503.633,48 hectares $(13,50 \%)$ e São Paulo, com 496.722,21 hectares (13,31\%), como evidencia a tabela 02.

Em relação ao número de imóveis, São Paulo é o estado que apresenta concentração mais expressiva, com 11.322 propriedades registradas em nome de estrangeiros (41,65\%), seguido do Paraná, com 4.795 imóveis (17,64\%) e Rio de Janeiro, com 1.823 imóveis declarados junto ao INCRA (6,71\%). Examinando conjuntamente a extensão de terras e quantidade de propriedades declaradas por estrangeiros é possível constatar que o estado do Mato Grosso apresenta uma maior concentração fundiária, uma vez que possui 2,52\% das propriedades. Em São Paulo, embora a extensão detida por estrangeiros não seja pequena, a quantidade de imóveis é a mais expressiva - 41,65\% - demonstrando uma menor concentração.

Tabela 02: Brasil - Propriedades e área em posse de estrangeiros (2021).

\begin{tabular}{|c|c|c|c|c|}
\hline \multirow{2}{*}{$\mathbf{U F}$} & \multicolumn{2}{|c|}{ Área } & \multicolumn{2}{|c|}{ N. de imóveis } \\
\hline & Hectares & $\%$ & Quantidade & $\%$ \\
\hline Mato Grosso & $828.985,84$ & 22,22 & 686 & 2,52 \\
\hline Mato Grosso do Sul & $503.633,48$ & 13,50 & 872 & 3,21 \\
\hline São Paulo & $496.722,21$ & 13,31 & 11.322 & 41,65 \\
\hline Paraná & $354.587,05$ & 9,50 & 4.795 & 17,64 \\
\hline Bahia & 223.304 & 5,98 & 951 & 3,49 \\
\hline Pará & $203.883,57$ & 5,46 & 1.089 & 4,01 \\
\hline Goiás & $193.737,48$ & 5,19 & 708 & 2,61 \\
\hline Minas Gerais & $183.010,92$ & 4,90 & 1.251 & 4,61 \\
\hline Tocantins & $168.296,77$ & 4,51 & 171 & 0,62 \\
\hline Rio Grande do Sul & $121.484,10$ & 3,25 & 1.054 & 3,87 \\
\hline Amazonas & $105.418,28$ & 2,81 & 235 & 0,86 \\
\hline Piauí & $70.021,82$ & 1,88 & 79 & 0,31 \\
\hline Rio de Janeiro & $56.977,40$ & 1,60 & 1.823 & 6,71 \\
\hline Maranhão & $54.870,57$ & 1,47 & 107 & 0,39 \\
\hline Rondônia & $32.935,79$ & 0,88 & 150 & 0,55 \\
\hline Roraima & $28.529,14$ & 0,76 & 54 & 0,21 \\
\hline Santa Catarina & $28.139,21$ & 0,75 & 714 & 2,62 \\
\hline Ceará & $18.556,92$ & 0,49 & 226 & 0,83 \\
\hline Espírito Santo & 11.265 & 0,31 & 176 & 0,64 \\
\hline Rio Grande do Norte & $11.082,97$ & 0,31 & 97 & 0,35 \\
\hline Acre & 10.383 & 0,30 & 29 & 0,11 \\
\hline Pernambuco & $9.759,04$ & 0,26 & 220 & 0,81 \\
\hline Distrito Federal & $4.848,04$ & 0,13 & 215 & 0,79 \\
\hline
\end{tabular}




\begin{tabular}{c|c|c|c|c} 
Paraíba & $3.230,67$ & 0,08 & 78 & 0,29 \\
\hline Amapá & 2.789 & 0,07 & 8 & 0,02 \\
\hline Sergipe & $2.409,73$ & 0,06 & 44 & 0,16 \\
\hline Alagoas & 526 & 0,01 & 28 & 0,11 \\
\hline Total & $\mathbf{3 . 7 2 9 . 3 8 8 , 0 0}$ & $\mathbf{1 0 0}$ & $\mathbf{2 7 . 1 8 2}$ & $\mathbf{1 0 0}$ \\
\hline
\end{tabular}

Fonte: SNCR (01 mai. 2021). Org.: Autora (2021).

Nesta conjuntura complexa de avanço da estrangeirização e restrição da fiscalização, iniciativas de criação de bancos de dados tornam-se cada vez mais frequentes. Um exemplo é o Land Matrix ${ }^{5}$, que corresponde a uma iniciativa independente de monitoramento de Grandes Transações de Terras (GTT) em países de rendas médias e baixas. O interessante é que o Land Matrix considera diferentes formas de controle da terra e não apenas terras compradas, como o SNCR/INCRA, sendo registradas terras controladas via arrendamentos, concessões e contratos. Segundo os dados do Land Matrix (2021), entre 2000 e 2021 foram transacionados 3.909.231 hectares de terras no país por meio de 110 operações, todas, de alguma forma, vinculadas ao capital estrangeiro ${ }^{6}$.

No que tange ao uso do território, de acordo com o Land Matrix, 25,3\% destas terras são destinadas ao cultivo de eucalipto, seguido da soja (18,7\%) e do milho (11,3\%), todos classificados como commodities flexíveis. Em cada estado há suas particularidades em relação as territorialidades e dinâmicas da estrangeirização. No estado de São Paulo a cana-de-açúcar é dominante, já na região Sul (sobretudo no Paraná e Rio Grande do Sul) a silvicultura apresenta maior expressividade, no oeste da Bahia a produção de grãos é hegemônica, enquanto no sul baiano a silvicultura domina. Assim, a estrangeirização da terra no Brasil é marcada pelas particularidades e continuidades.

\section{AS TERRITORIALIDADES DA ESTRANGEIRIZAÇÃO DA TERRA NO NORDESTE}

Em ambos os bancos de informações utilizados na pesquisa, o Nordeste brasileiro desponta expressividade, embora ocupe a última posição no ranking das macrorregiões com presença de capital estrangeiros em terras agrícolas. De acordo com o SNRC/INCRA, o Nordeste concentra 393.762

\footnotetext{
${ }^{5}$ As transações cadastradas no portal respeitam os seguintes critérios: superfície transacionada igual ou maior a 200 hectares, negociação ocorrida após o ano 2000, alteração da propriedade/controle da terra e do uso do solo. As transações registradas pelo Land Matrix não correspondem apenas aos agentes estrangeiros. O Land Matrix foi alvo de constantes críticas por parte da academia, especialmente pelo caráter enviesado dos dados e ausência de verificação/confirmação da s informações coletadas (OYA, 2013). Embora se compreenda as lacunas do banco de dados sobre a temática, é o mais completo e coerente na atualidade, permitindo realizar uma análise global do processo.

${ }^{6}$ Em parte dos casos empresa operadora é declarada como de capital nacional, mas possui investidores estrangeiros, sejam estas empresas terceiras ou fundos de investimento.
} 
hectares (10,54\%) em 1.830 imóveis (6,74\%). Já no Land Matrix (2021) há 30 transações sistematizadas, com 1.255.021,00 hectares transacionados, ou seja, quase o triplo do computado pelo SNCR. A maioria dos casos registrados pelo Land Matrix está localizado nas porções dos estados da Bahia e Piauí que compõem o MATOPIBA, considerada a fronteira da estrangeirização (PEREIRA e PAULI, 2019).

As territorialidades da estrangeirização da terra no Nordeste são múltiplas, porém, segundo as informações do portal Land Matrix (2021), se destacam a cana-de-açúcar, a silvicultura, grãos em rotação (soja e milho), algodão e frutas. A agricultura canavieira é central no processo de formação espacial do Nordeste e, na atualidade, embora os estados do Centro-Sul (em especial São Paulo e Minas Gerais) concentrem a produção de cana, o Nordeste ainda exerce um importante papel, com 879.971 hectares cultivados em 2019 (PAM/IBGE, 2019a), com atenção para os estados de Alagoas (304.748 hectares), Pernambuco (228 177 hectares) e Paraíba (97.751 hectares).

Empresas estrangeiras do setor sucroenergético passaram a atuar na região por meio da aquisição de antigas plantas processadoras que, na sua maioria, estavam em processo de recuperação judicial ou pertenciam a famílias regionais com atuação histórica no setor. A partir do início dos anos 2000 plantas no Rio Grande do Norte e na Paraíba foram adquiridas pela empresa Biosev, que pertence ao grupo francês Louis Dreyfus Company. Porém, recentemente o grupo vendeu suas plantas processadoras no Nordeste, centrando a sua atuação nos estados de São Paulo, Minas Gerais, Goiás e Mato Grosso do Sul.

Na produção de grãos, há o predomínio da soja, que apresenta um importante peso na balança comercial. Em 2019, foram cultivados 35.930.334 hectares de soja, totalizando 114.269.392 toneladas produzidas no mesmo ano (IBGE, 2019a). No Nordeste a área destinada a soja foi de 3.328.625 hectares, com 10.499.942 toneladas produzidas. Apesar da produção de soja se concentrar no CentroSul, especialmente Mato Grosso e Rio Grande do Sul, os estados da Bahia, Maranhão e Piauí tem apresentado um crescimento vertiginoso do cultivo do grão.

Os municípios que apresentam maior incidência da soja estão inseridos no MATOPIBA, que foi um sucesso para o agronegócio e para os latifundiários da região. O êxito foi tão importante que inspirou outra regionalização proposta pela EMBRAPA, a SEALBA, que é formada por 171 municípios dos estados do Sergipe (63), Alagoas (74) e Bahia (28) (EMBRAPA TABULEIROS COSTEIROS, 2019). Dentre os diferentes cultivos, as pesquisas no âmbito da SEALBA têm focado especialmente na produção da soja na região. 
A fruticultura é outra expressão da estrangeirização no Nordeste, tem apesentado um aumento significativo, sendo responsável pela dinamização da economia de diversos municípios, especialmente em áreas de perímetro irrigado. Bezerra (2012) destaca que o Nordeste apresenta um quadro importante na produção de frutas tropicais com destino a exportação in natura, isso é, sem processamento, o que torna o "Nordeste uma região extremamente competitiva no cenário nacional e internacional" (BEZERRA, 2012, p. 135). No ano de 2018, 660.181 hectares foram destinados ao cultivo de banana, mamão, manga, melão e uva no Brasil. Deste total, 277.331 hectares eram no Nordeste, ou seja, a região concentrava $42,31 \%$ da área destinada a produção das respectivas frutas no Brasil (PAM/IBGE, 2020a).

Um exemplo é a Del Monte Fresh Fruit, empresa estadunidense com atuação histórica na América Latina (BURBACH e FLYNN, 1982) e que possui fazendas em municípios do Rio Grande do Norte e do Ceará (em Quixeré e Limoeiro do Norte). Segundo Cavalcante (2020) atualmente a Del Monte está versada apenas na produção de banana e coco verde, contudo, em tempos pretéritos, possuía uma relevante produção de abacaxi e melão, com uma área de cerca de 6.000 hectares apenas no Ceará. Ainda segundo Cavalcante (2020, p. 33) "toda sua produção é destinada para exportação, notadamente para os Estados Unidos e Europa". A fruticultura traz conflitos territoriais, inclusive envolvendo as dimensões da luta pela água e contra a utilização de agrotóxicos, como o exemplo do Vale do Jaguaribe, no estado do Ceará (SOUSA et al., 2019).

A silvicultura, por meio do cultivo de eucalipto, tem se materializado como uma expressão viva da estrangeirização no Nordeste. Segundo as informações da Produção da Extração Vegetal e da Silvicultura (PEVS), do IBGE, foram cultivados 7.616.184 hectares de eucalipto no Brasil, sendo 927.205 hectares no Nordeste. Na região, os estados da Bahia e Maranhão concentram a maior parte da produção, com 599.562 e 268.417 cultivados em 2019, respectivamente (IBGE, 2020b). O Sul da Bahia é área de produção tradicional de florestas plantadas, com a presença contraditória da Veracel Celulose S.A., joint-venture entre a Suzano Papel e Celulose (antiga Fibria ${ }^{7}$ ) e a sueco-finlandesa Stora Enso Brasil Ltda. (DATALUTA, 2018). A mesorregião do Oeste Maranhense, que tem se apresentado como fronteira de expansão do cultivo de eucalipto, especialmente na microrregião de Imperatriz, onde a empresa responsável pela expansão do cultivo é a Suzano, que atua através da compra de imóveis rurais e arrendamento.

\footnotetext{
${ }^{7}$ A empresa brasileira com presença de capital estrangeiro Fibria foi adquirida em 2019 pela empresa Suzano Papel e Celulose (DATALUTA, 2018).
} 
Ainda acerca da silvicultura, é importante se acompanhar a evolução do cultivo de eucalipto no estado de Alagoas. Segundo Lima et al. (2020) a superfície destinada ao plantio da árvore cresceu exponencialmente na última década, ocupando, inclusive, áreas tradicionalmente destinadas ao cultivo da cana-de-açúcar. O caso mais representativo é a Duratex Florestal S.A., que, desde 2016, controla diretamente (via compra) cerca de 6.000 hectares em Alagoas através da joint venture com a Usina Caeté, formando a Caetex Florestal S.A. (LIMA, et al., 2020).

A mineração tem sido materializada no Nordeste há décadas, inclusive ainda no ano de 1987 Manoel Correia de Andrade já sublinhava a expressividade da produção de minerais não metálicos como a fosforita, o calcário, a argila e a xelita (ANDRADE, 1987). Como todos os outros recursos, a exploração mineral tem adquirindo maior expressividade no século XXI. As áreas das atividades mineiras são de interesse nacional, logo necessitam de autorizações especiais para a exploração pelo capital estrangeiro (vide Lei n. 5.709/71). Mesmo assim, tais agentes têm se territorializado e controlado grandes extensões de terra com o intuito de acessar o subsolo para a exploração. Ademais de explorar os minérios, cria-se toda uma infraestrutura para comercialização e exportação do mesmo através de ferrovias, minerodutos e portos.

Um exemplo da atuação estrangeira no setor é o Projeto de Mineração Pedra de Ferro, localizado, sobretudo, nos municípios de Caetité e Pindaí, na Bahia, anunciado pelo governo estadual como "polo emergente da mineração do Brasil" (OLIVEIRA e BRITO, 2020). O projeto pertencente à mineradora Bahia Mineração S.A, que, segundo o Movimento pela Soberania Popular na Mineração (MAM) (27 jul. 2018), tem na sua composição acionária uma empresa com sede no Cazaquistão (majoritária) e outra com sede em Luxemburgo.

Entretanto, há outros usos do território que tem emergido velozmente em todo o Brasil, mas com densidade no Nordeste e que aos poucos vem sendo objetos de pesquisas em diferentes áreas do conhecimento, como é o caso das energias renováveis (eólica e fotovoltaica), que nem sempre são registradas devido a forma de acesso à terra (arrendamento) e que vem sendo associada a ideia de progresso (LEITE e PICCHI, 2019). A geração de energia oriunda de outras fontes é incentivada pelo Estado brasileiro desde 2001, momento o qual ocorreu uma crise elétrica decorrente da escassez de chuvas e que, consequentemente, afetou a produção e oferta de energia hidrelétrica, episódio conhecido como “Apagão” (TRALDI, 2019). Ainda em 2001 foram lançadas políticas públicas como o Programa Emergencial de Energia Eólica (PROEÓLICA) e o Atlas do potencial eólico brasileiro, cujo objetivo "é fornecer informações para capacitar tomadores de decisão na identificação de áreas 
adequadas para aproveitamentos eólico-elétricos" (AMARANTE, BROWER, ZACK e SÁ, 2001, p. $06)$.

Todavia, mesmo com todo o incentivo por parte do Governo Federal, de 2001 a 2008 apenas 52 parques eólicos foram outorgados no país (SIGA/ANEEL, 2021). A partir de 2009 uma onda de interesse na energia eólica é iniciada no Brasil, decorrente do interesse do capital internacional em novos mercados, bastante alicerçado na convergência de múltiplas crises. Segundo Traldi (2019, p. 86) “novas contratações da fonte eólica só vieram a ocorrer em dezembro de 2009, após o início da crise econômica internacional de 2008, quando foi promovido um leilão exclusivo para a fonte eólica para contratação de energia de reserva”. Assim, a energia eólica tem a sua expansão no Brasil estritamente vinculada aos interesses de agentes internacionais.

Segundo os dados do Sistema de Informações de Geração da Agência Nacional de Energia Elétrica (SIGA/ANEEL) existem 1.036 parques eólicos no Brasil com o potencial eólico de 18.075.472,86 MW, sendo: 713 (18.075.472,86 MW) em operação, 146 em construção (4 679 580,00 MW) e 177 (7002130,00 MW) outorgados, mas sem a construção iniciada. Deste total, 930 empreendimentos estão localizados no Nordeste, sendo 610 em operação, 143 em construção e 177 outorgados (sem a construção iniciada), o que significa que praticamente todos os parques em construção e aprovados estão na região. O Nordeste é a região que apresenta o maior potencial eólico do Brasil, sendo o semiárido a principal área de produção e expansão dos parques eólicos (TRALDI, 2019).

Para instalar um aerogerador é necessário ter acesso à terra, que tem ocorrido, majoritariamente, por meio o arrendamento fundiário ${ }^{8}$. A prática de arrendamento tem ocorrido em todo o Nordeste, resultando em conflitos territoriais diretos, uma vez que os camponeses são impedidos de manterem seus cultivos e os preços pagos pelo arrendamento são baixos, sem mencionar o longo período destes contratos, variando de 25 a 35 anos e podendo ser automaticamente renovados caso seja de interesse da empresa (LEITE e PICCHI, 2019).

\footnotetext{
${ }^{8}$ Ao tratar da renda da terra, Marx (2017, p. 679) pontua que o capitalista arrendatário "paga ao proprietário fundiário, proprietário da terra por ele explorada, em prazos determinados, digamos anualmente, uma soma de dinheiro fixada por contrato em troca da permissão para aplicar seu capital nesse campo particular da produção. Essa soma de dinheiro se chama renda fundiária, não importando se é paga por terra agricultável, terreno para construções, minas, pesqueiros, bosques, etc.".
} 
Está prática tem ocorrido, inclusive, em terras de assentamentos de reforma agrária, como o caso do assentamento Zumbi/Rio do Fogo no Rio Grande do Norte ${ }^{9}$, que desde 2005 sofre as consequências da instalação do parque eólico RN 15 - Rio do Fogo e desde 2013 com a expansão e criação do parque Arizona 1 (FERRAZ, 2015). O parque RN 15 - Rio do Fogo pertencente a empresa Enerbrasil - Energias Renováveis do Brasil S.A. (que tem na sua composição acionária a empresa Iberdrola Operação e Manutenção Ltda.) e o empreendimento Arizona 1 é de responsabilidade da Iberdrola (controlada pela espanhola Neoenergia) (SIGA/ANEEL, 2021). No caso específico deste assentamento, foi firmado um contrato em 2003 entre a empresa operadora (Enerbrasil) e INCRA, o parque começou a operar em 2006 (FERRAZ, 2015).

A Bahia também se sobressai na instalação de projetos eólicos. Exitem 192 parques em operação e mais 127 estão outorgados (60 com construção iniciada e 67 ainda não iniciados) (SIGA/ANEEL, 2021). Os municípios da mesorregião Centro-Sul Baiano se destacam, sobretudo Caetité, Licínio de Almeida, Tanque Novo, Guanambi, Brumado, Igaporã e Pindaí, que sozinhos concentram 95 parques. Documento publicado pela Comissão Pastoral da Terra (CPT) em agosto de 2013, já destacava as alterações na paisagem e no modo de vida das populações, tanto do campo como da cidade. A ameaça e perda de territórios, a migração forçada, a grilagem, a violência e a criminalização fazem parte do cotidiano destas populações.

A energia fotovoltaica apresenta crescimento exponencial desde 2008. Segundo o SIGA/ANEEL (2021) existem 4.202 unidades geradoras de energia fotovoltaica no Brasil. O Nordeste concentra 274 parques (78 em operação, 12 em construção e 184 outorgados, porém sem iniciar a construção). Bahia, Ceará e Piauí são as unidades da federação que mais se destacam, com 75, 65 e 51 projetos, respectivamente. Analisando os dados disponibilizados pelo SIGA/ANEEL e acompanhando as notícias publicadas na grande mídia sobre o setor, é possível observar que a expansão da energia fotovoltaica ocorre em um menor grau do que a energia eólica, porém há muitos projetos já aprovados sem data prevista para a implementação.

Todos estes usos do território pelo capital estrangeiro resultam em conflitos territoriais, que corresponde ao momento direto do enfrentamento e em conflitualidade, que corresponde ao processo de "enfretamento perene que explicita o paradoxo das contradições e as desigualdades do sistema capitalista, evidenciando a necessidade do debate permanente, nos planos teóricos e práticos, a

\footnotetext{
${ }^{9}$ A área com maior potencial eólico no estado do Rio Grande do Norte é justamente a região que concentra os assentamentos de reforma agrária.
} 
respeito do controle político e de modelos de desenvolvimento" (FERNANDES, 2008, p. 217). Cada territorialidade possui suas especificidades que incluem as dinâmicas, as formas de controle e acesso à terra.

\section{A ATUALIDADE DA ESTRANGEIRIZAÇÃO NO TERRITÓRIO PARAIBANO}

Moreira e Targino (1996) pontuam que o espaço agrário paraibano desde o início da colonização tem-se constituído como um espaço de exploração. No século XXI isso se mantem, o que ocorre é apenas um novo arranjo da estrangeirização da terra. Existem novos elementos e características do processo no território paraibano que refletem a própria lógica que a estrangeirização assume em escala global, nacional (Brasil) e regional (Nordeste). Como já exposto no tópico anterior a região Nordeste apresenta uma complexidade ímpar e o estado da Paraíba não foge à regra.

De fato, a Paraíba não é a unidade da federação na qual a estrangeirização se faz mais presente. Todavia, a dinâmica que tem adquirido nos últimos anos merece destaque. As múltiplas territorialidades é uma das mais emblemáticas alterações do arranjo da estrangeirização. Além da produção agrícola, bastante centrada na produção canavieira, emergem outros usos do território, todos alicerçados na exploração massiva dos recursos e na geração de impactos territoriais.

Segundo os dados do SNCR (2021) foram declarados 3.230,67 hectares de terras sob propriedade de estrangeiros no estado, totalizando 78 propriedades em 34 municípios. Ainda segundo as informações disponíveis no SNCR, as nacionalidades dominantes são os portugueses (1.012,14 hectares), suíços (430,14 hectares), argentinos (327,08 hectares), belgas (311,80 hectares) e chineses (259,05 hectares). Nenhuma das empresas levantadas na pesquisa possuem terras declaradas no SNCR, o que pode ser explicado, em alguns casos, pelo fato das terras serem arrendadas.

A primeira territorialidade da estrangeirização no estado é a cana-de-açúcar, cultivo que faz parte da formação espacial da Paraíba (MOREIRA e TARGINO, 1996). A atuação estrangeira no setor ocorre mediante a incorporação de antigas usinas e engenhos. Um exemplo é a Alcotra BioEnergy do Brasil S.A., empresa com presença de capital belga que, em 2007, adquiriu a Destilaria Tabu, localizada em Caaporã, na Paraíba e que era propriedade do Grupo Lundgren. A Destilaria Tabu foi construida pelo grupo na segunda metade da década de 1970 através de recursos do Programa Nacional do Álcool (PROÁLCOOL) (MOREIRA, BONOLO e TARGINO, 2014).

Em 2006 a Usina Gramane Industrial e Agrícola S.A., popularmente conhecida como Giasa e localizada em Pedras de Fogo, na Zona da Mata paraibana, foi adquirida pelo grupo francês Louis 
Dreyfus Company, por meio da Biosev. A Giasa era propriedade do grupo Tavares de Melo, formado em 1920 para a atuação em engenhos em Pernambuco (MOREIRA, BONOLO e TARGINO, 2014). Além da usina na Paraíba, datada de 1971, o grupo Tavares de Melo fundou usinas no Rio Grande do Norte (1969) e no Mato Grosso do Sul (1982 e 1985), todas incorporadas pela Louis Dreyfus Company no século XXI. Em novembro de 2018, a Biosev concluiu a venda da Usina Giasa à M\&N Participações S.A., holding do Grupo Olho D’Água, de atuação tradicional no Nordeste, por um montante de R $\$ 70.000 .000,00$ (NOVA CANA, 12 nov. 2018).

A mineração é um setor no qual a presença do capital estrangeiro é forte, especialmente na extração de minerais não metálicos no Seridó e na Zona da Mata paraibana (MOREIRA, BONOLO e TARGINO, 2014). Os minerais mais explorados são a bentonita, o calcário, a argila comum e plástica e pedras ornamentais como o granito e o feldspato (MOREIRA, BONOLO e TARGINO, 2014).

Em Mataraca, no litoral norte da Paraíba, a exploração é de titânio. A estadunidense Millennium Inorganic Chemicals adquiriu a então Tibrás, que detinha a Mina do Grajaú, alterando a sua razão social para Millennium Inorganic Chemicals do Brasil S.A. em 1998. Segundo Sousa, Oliveira e Moreira (2014), em 2004 a Millennium foi incorporada ao Grupo Lyondell, em 2007 foi vendida a empresa Cristal Company, afiliada da Saudi Arabias National Industrialisation Co. e desde 2013 possui a razão social Cristal Pigmentos do Brasil S.A. Em 2017 a Cristal Pigmentos do Brasil S.A. foi vendida pelo grupo saudita Tasnee ao grupo estadunidense Tronox por US\$1,67 bilhão e passou a utilizar o nome Tronox Pigmentos do Brasil S.A. (VALOR ECONÔMICO, 21 fev. 2017). O exemplo da Mina do Grajaú evidencia como a estrangeirização é dinâmica e como os controles acionários se alteram constantemente.

A energia eólica é outro uso do território que tem emergido em meio a controvérsias. Atualmente há 15 parques em operação, totalizando 157.200,00 KW de potência outorgada. Somados a estes existem 15 parques em construção e nove aprovados, porém sem início das obras. Os primeiros parques tiveram vigência outorgada em 2004, porém as operações iniciaram apenas a partir de 2007, todos no município de Mataraca, litoral norte, conhecido pela exploração de titânio, como acima citado. Dos doze parques eólicos existentes em Matacara, nove pertencem ao Vale dos Ventos Geradora Eólica S.A., que hoje, está sob controle da Pacific Hydro Energia do Brasil Ltda., que, por sua vez, é subsidiária da State Power Investment Corporation of China (SPIC BRASIL, 2021). Há outros dois parques eólicos em Mataraca, um pertente a SPE Millennium Central Geradora Eólica 
S.A. (que também é controlada pela State Power Investment Corporation of China) e o outro é de propriedade da Cardus Energia Ltda. (SIGA/ANEEL, 2021).

Somados ao complexo eólico territorializado em Mataraca, há mais três parques eólicos em operação localizados em São José do Sabugi (dois parques) e em Santa Luzia, no semiárido paraibano. Os três empreendimentos foram outorgados em 2015, já no período de avanço da fronteira energética rumo ao semiárido, com a operação iniciada em 2017. Um dos parques implantados em São José do Sabugi pertence a Canoas Energia Renovável S.A. Já o segundo empreendimento instalado no município é de propriedade da Lagoa 2 Energia Renovável S.A. O parque localizado em Santa Luzia é de totalmente controlado pela Lagoa 1 Energia Renovável S.A. As três empresas pertencem ao grupo espanhol Neoenergia.

Acerca dos parques eólicos em construção, nove estão localizados em Santa Luzia, três ocupam áreas em Areia de Baraúnas e Santa Luzia, um está entre Areia de Baraúnas e São Mamede e, por fim, há dois projetos iniciados em São José do Sabugi, totalizando 471.240,00 KW de potência outorgada. Todas as empresas operadoras dos parques em construção são de propriedade da espanhola Neoenergia. Há nove projetos aprovados, mas sem construção iniciada. Sete estão situados em Junco do Seridó e dois em Santa Luzia, totalizando 329.175,00 KW de potência outorgada. Todos os parques são de empresas operadas pelo grupo francês EDF Renewables, com o total de R \$1 bilhão investido no estado (CANAL ENERGIA, 29 abr. 2021). O protocolo de intenções foi assinado entre EDF e o governador da Paraíba, João Azevêdo (Cidadania), em abril de 2021, as obras estão previstas para julho de 2021 com início da operação comercial apenas em 2023 (CANAL ENERGIA, 29 abr. 2021).

Assim, com exceção do empreendimento da Cardus Energia Ltda. em Mataraca, todos os parques eólicos em operação, em construção e previstos na Paraíba são controlados por empresas estrangeiras. O capital chinês já está em operação (Mataraca), o capital espanhol está em construção (Santa Luzia/São José do Sabugi/Areia de Baraúnas) e o capital francês com construção prevista (Junco do Seridó/Santa Luzia). Os parques instalados anterior à 2008 estão localizados no litoral, enquanto os demais estão no seminário, respeitando a nova fronteira da energia eólica no Brasil (TRALDI, 2019).

Impactos destes parques tem sido o aumento do preço da terra, em Santa Luzia o preço da terra elevou de "R\$200,00 o hectare para R\$2.000, além da regularização fundiária, em que a empresa assume os custos junto aos cartórios e prefeituras antes de firmarem os contratos de arrendamento" (CARTAXO, 2020, p. 84). Entretanto, o preço do arrendamento não é alterado com a 
valorização, uma vez que os contratos são firmados a longo prazo, em Santa Luzia, o preço médio é de $\mathrm{R} \$ 600,00$ caso o proprietário tenha até 100 hectares, recebendo mais $\mathrm{R} \$ 2,00$ por hectare se o tamanho exceder uma centena (CARTAXO, 2020).

Muito em decorrência da implantação recente dos projetos, especialmente no semiárido paraibano, não se sabe ao certo as alterações no uso do território por parte da população rural arrendatária. Em outros locais é frequente relatos de que mesmo com o discurso "vendido" de que os camponeses arrendatários conseguem produzir seus cultivos agrícolas em convivência com os aerogeradores, tal prática não é possível, como relata Hofstaetter (2016) a partir dos parques localizados no Rio Grande do Norte. A tendência é de os moradores criarem uma expectativa positiva acerca dos empreendimentos, que nem sempre é respondida.

Costa (2018), ao pesquisar as alterações decorrentes dos parques eólicos em Santa Luzia, São José do Sabugi e Junco do Seridó, verificou por meio da aplicação de questionários que poucos fora os beneficiados da instalação, seguindo a tendência nacional do processo. Na realidade o que ocorre nas áreas destinadas à implantação de parques eólicos na Paraíba "é uma desestruturação das bases socioeconômicas e uma grande apropriação do discurso ambiental para justificar um negócio extremamente rentável as multinacionais e que no fim, não há retorno para os município e comunidades ali existentes" (LEITE e PICCHI, 2019, p. 15)

Já a energia fotovoltaica, na Paraíba há 26 projetos outorgados, sendo sete em operação (136.166,4 KW), três em construção $(81.000,00 \mathrm{KW})$ e 16 ainda não iniciados $(494.590,00 \mathrm{KW})$ (SIGA/ANEEL, 2021). Os dois primeiros parques fotovoltaicos da Paraíba iniciaram operação em setembro de 2018, nos municípios de Condado e Coremas, ambos na mesorregião do Sertão Paraibano. Dos parques previstos, doze estão localizados em Coremas, dois em São José da Lagoa Tapada, dois em Santa Luzia, dois em São João do Rio do Peixe e um em Malta.

O Complexo Solar de Coremas, que envolve parques nas três fases (operação, construção e aprovado), é uma parceria de uma empresa dinamarquesa e da desenvolvedora de projetos de energia renovável brasileira chamada de Rio Alto Energias Renováveis. O complexo conta com financiamento do Banco do Nordeste com apoio do Ministério de Minas e Energia e do governo federal (CHESF, 17 set. 2020), o que evidencia a importância do apoio estatal a estes empreendimentos, o que nem sempre retorna em benefício da população local.

As territorialidades da estrangeirização na Paraíba vem se complexificando no decorrer dos anos, cada vez com novos arranjos e rumo ao semiárido. Todo o território passa a ser incorporado 
pelo capital hegemônico estrangeiro que, por sua vez, utiliza de um discurso de progresso e de desenvolvimento sustentável (no caso das energias renováveis) para expandir a sua atuação e justificar o controle sobre os recursos naturais que lhes são de interesse. Para a população local, o que tem sobrado são as expectativas de recompensa, de geração de empregos e de melhores condições de vida. Porém, não passam de promessas, porque na realidade o que ocorre é a alteração dos modos de vida em todas as dimensões.

\section{CONSIDERAÇÕES FINAIS}

A estrangeirização, entendida como um processo do controle do território nas suas múltiplas dimensões e escalas, é histórica no Brasil. O sentido da estrangeirização sempre foi o mesmo, garantir a acumulação do capital, especialmente em tempos de crise, o que altera são apenas os arranjos. Diante de um contexto caracterizado pela convergência de múltiplas crises e pelas mudanças geopolíticas globais, a estrangeirização tende a se tornar mais complexas, porém sem perder a sua essência, que promove a concentração de terras e capital, a exploração de recursos e do trabalho e a alteração de modos de vida.

Não é de agora que a apropriação de terras por estrangeiros preocupa a população e o Estado brasileiro. Desde 1971 a Lei n. 5.709 está em vigência justamente com o objetivo de controlar este processo. Em meio a recente intensificação da corrida mundial por terras novos Pareceres foram promulgados (como o Parecer LA 01 da AGU, datado de agosto de 2010) com o intuito não apenas de restringir a estrangeirização no Brasil, mas de saber quais terras são controladas por estrangeiros, considerando que é uma questão de segurança nacional.

Porém há lacunas que historicamente são utilizadas por parte de agentes da estrangeirização para propiciar a sua ação no território, como por exemplo os registros de imóveis rurais em propriedade de terceiros, os contratos de concessão e arrendamento, dentre outros. Ademais, considerar apenas a compra como forma de acesso à terra pelo capital estrangeiro reduz o processo, uma vez que o controle ocorre por meio de estratégias que não necessitam do título de propriedade. Soma-se ainda o fato de as terras serem autodeclaradas e sem uma fiscalização efetiva por parte do INCRA, órgão que também tem sofrido com os cortes orçamentários e militarização.

No Brasil, segundo dados atuais do SNCR (01 mai. 2021), o montante de 3.729.388,00 hectares é de propriedade de estrangeiros, totalizando em 27.182 imóveis rurais. Porém, diante de toda a dinâmica complexa que a estrangeirização assume no Brasil, mediante de todas as lacunas na 
legislação e na forma como o Estado tem considerado o processo, a estimativa é que a quantidade de terras sob o controle de estrangeiros seja bem maior. Apenas o fato de o SNCR não considerar as terras arrendadas à estrangeiros para a implantação de parques eólicos evidencia como os dados oficiais não correspondem à realidade.

Embora o Nordeste não seja a região mais expressiva no quesito de terras em posse de estrangeiros (considerando os dados oficiais do SNCR/INCRA), é a que tem apresentado a maior complexidade da estrangeirização, sobretudo em decorrência dos novos usos do território pelo capital estrangeiro, o que tem inserido a região, particularmente o semiárido, como a fronteira da exploração dos recursos energéticos renováveis no Brasil. Os projetos eólicos e fotovoltaicos trazem consigo novas narrativas e novas formas de acesso e apropriação de territórios tradicionais. Em meio a um discurso de sustentabilidade, altera a paisagem e os modos de vida locais e, ao final, o objetivo é o mesmo de 500 anos atrás: garantir a acumulação de capital.

Além das energias renováveis, a estrangeirização é materializada no Nordeste através da cana-de-açúcar, da silvicultura, dos grãos, da fruticultura e da exploração mineral, todas em constante ascensão, em especial esta última, uma vez que há diferentes projetos de mineração em discussão na região. Assim, o capital estrangeiro controla a terra para acessar o subsolo (mineração), os ventos (eólica), a luz solar (fotovoltaica), a fertilidade e as águas (produção agrícola). No Nordeste ainda, futuras possibilidade de análises é a estrangeirização pautada na apropriação da paisagem para a promoção da atividade turística, especialmente por meio da criação de resorts.

A Paraíba segue a tendência da diversidade da estrangeirização no Nordeste. Atualmente a cana-de-açúcar, a mineração (titânio e minerais não metálicos) e as energias renováveis (eólica e fotovoltaica) se convergem na disputa pelo território paraibano. No caso da cana-de-açúcar, o controle tem ocorrido por meio da aquisição de antigas plantas agroindustriais, implantadas em tempos de programas de incentivo a produção do álcool, como o PROÁLCOOL. No caso de mineração, o acesso ocorre mediante concessão de uso e exploração e, nos casos das energias renováveis este a atuação estrangeira ocorre por meio do arredamento fundiário.

Os conflitos e conflitualidades são inerentes a todas as formas na qual a estrangeirização se materializa na Paraíba. O modelo concentrador do controle do território pelo capital estrangeiro gera impactos visíveis na paisagem, resulta em consequências na produção agrícola, na renda e na segurança alimentar de toda a população que, de alguma forma, é atingida. Altera modos de vida de 
diversas comunidades tradicionais em prol de uma narrativa de progresso que na realidade não se concretiza.

\section{REFERÊNCIAS}

ALENTEJANO, Paulo Roberto Raposo. As políticas do Governo Bolsonaro para o campo: a contrareforma em marcha acelerada. Revista da ANPEGE, v. 16, n. 29, p. 353-392, 2020.

AMARANTE, Odilon A. Camargo do; BROWER, Michael; ZACK, John; SÁ, Antonio Leite de. Atlas do Potencial Eólico Brasileiro. Brasília: ANEEL, 2001.

ANDRADE, Manuel Correia de. Mineração no Nordeste: depoimentos e experiências. Brasília: CNPq, Assessoria Editorial e Divulgação Científica, 1987.

ANEEL. Sistema de Informações de Geração da ANEEL (SIGA). Brasília: Agência Nacional da Energia Elétrica, 2021. Disponível em: https://www.aneel.gov.br/siga. Acesso em: 30 mar. 2021.

BEZERRA, Juscelino Eudâmidas. A fruticultura no Nordeste Semiárido: internacionalização, conflitos territoriais e a precarização do trabalho. Presidente Prudente, 2012. 376f. Tese (Doutorado em Geografia) - Faculdade de Ciências e Tecnologia, Universidade Estadual Paulista, Presidente Prudente, 2012.

BORRAS JR, Saturnino et al. Transnational land investment web: land grabs, TNCs, and the challenge of global governance. Globalizations, v. 17, n. 4, p. 608-628, 2020.

BRASIL. Lei n. 5.709, de 07 de outubro de 1971. Regula a Aquisição de Imóvel Rural por estrangeiro Residente no País ou Pessoa Jurídica Estrangeira Autorizada a Funcionar no Brasil. Presidência da República Casa Civil - Subchefia para assuntos Jurídicos.

CANAL ENERGIA. Obras do primeiro parque eólico da EDF na Paraíba começam em julho. Canal Energia, caderno Expansão, publicado em 29 abr. 2021. Disponível em: https://www.canalenergia.com.br/noticias/53171016/obras-do-primeiro-parque-eolico-da-edf-naparaiba-comecam-em-julho. Acesso em: 22 mai. 2021.

CARTAXO, Ryan de B. Do litoral ao sertão: a energia eólica no estado da Paraíba. Revista Meio Ambiente e Sustentabilidade, v. 9, n. 19, p. 75-90, 2020

CASTRO, Luís Felipe Perdigão de; SAUER, Sérgio. Marcos legais e a liberação para investimento estrangeiro em terras no Brasil. MALUF, Renato; FLEXOR, Georges (Org.). Questões agrárias, agrícolas e rurais. Conjunturas e políticas públicas. Rio de Janeiro: E-papers, 2017, p. 39-51.

CAVALCANTE, Leandro Vieira. A territorialidade do capital no campo: agronegócio e uso corporativo do território no Ceará. Revista NERA, v. 23, n. 53, p. 22-46, mai.-ago., 2020. DOI: https://doi.org/10.47946/rnera.v0i53.6016

CHESF. Usina solar é inaugura em Coremas (PB). Companhia Hidrelétrica do São Francisco, página de notícias, publicado em 17 set. 2020. Disponível em: https://www.chesf.gov.br/_layouts/15/chesf_noticias_farm/noticia.aspx?idnoticia=638. Acesso em: 22 mai. 2021.

CORREIO BRAZILIENSE. Brasil não sabe a localização e o tamanho das terras controladas por multinacionais. Correio Braziliense, caderno Brasil, publicado em 21 jun. 2010. Disponível em: https://www.correiobraziliense.com.br/app/noticia/brasil/2010/06/21/interna-brasil,198607/brasil- 
nao-sabe-a-localizacao-e-o-tamanho-das-terras-controladas-por-multinacionais.shtml. Acesso em: 15 mai. 2021.

COSTA, Isis dos Santos. Perspectivas dos impactos socioeconômicos do complexo eólicos Canoas e Lagoas. Pau dos Ferros/RN, 2018, 70f. Monografia (Bacharelado em Ciência e Tecnologia). Universidade Federal Rural do Semiárido (UFERSA), Pau dos Ferros/RN, 2018.

CPT. O avanço do capital e sua influência nos modos de vida das populações tradicionais no município de Caetité (BA). Comissão Pastoral da Terra, caderno Artigos, publicado em 13 ago. 2013. Disponível em: https://www.cptnacional.org.br/publicacoes/noticias/artigos/1676-o-avancodo-capital-e-sua-influencia-nos-modos-de-vida-das-populacoes-tradicionais-no-municipio-decaetite-ba. Acesso em: 21 mai. 2021.

DATALUTA. Banco de Dados da Luta pela Terra, 2019. Disponível em: https://www.fct.unesp.br/\#!/pesquisa/dataluta/. Acesso em: 15 mai. 2021.

EDELMAN, Marc; OYA, Carlos; BORRAS JR., Saturnino. Global land grabs: historical processes, theoretical and methodological implications and current trajectories. Third World Quarterly, v. 34, n. 9 , p. $1517-1531,2013$.

EMBRAPA TABULEIROS COSTEIROS. Sealba: região de alto potencial agrícola no Nordeste brasileiro. Aracaju: EMBRAPA Tabuleiros Costeiros, 2019.

FAIRHEAD, James; LEACH, Melissa; SCOONES, Ian. Green Grabbing: a new appropriation of nature? The Journal of Peasant Studies, v. 39, n. 02, 237-261, 2012.

FERNANDES, Bernardo Mançano. Conflitualidade e desenvolvimento territorial. BUAINAIN, Antônio Márcio (Org.). Luta pela terra, reforma agrária e gestão de conflitos no Brasil. Campinas: Editora da UNICAMP, p. 173-224, 2008.

FERRAZ, Ednaldo Emilio. Energia eólica em assentamentos de reforma agrária: território em disputa - o caso do assentamento Zumbi/Rio do Fogo no Rio Grande do Norte. Natal, 2015. 117f. Dissertação (Mestrado em Ciências Sociais) - Centro de Ciências Humanas, Letras e Artes, Universidade Federal do Rio Grande do Norte, Natal, 2015.

FREDERICO, Samuel; ALMEIDA, Marina Castro de. Capital financeiro, land grabbing e a multiescalaridade na grilagem de terra na região do MATOPIBA. Revista NERA, v. 22, n. 47, p. 123147, dossiê MATOPIBA, 2019.

HOFSTAETTER, Moema. Energia eólica: entre ventos, impactos e vulnerabilidades socioambientais no Rio Grande do Norte. Natal, 2016. 176f. Dissertação (Mestrado em Estudos Urbanos e Regionais) - Centro de Ciências Humanas, Letras e Artes, Universidade Federal do Rio Grande do Norte, Natal, 2016.

IBGE. Produção Agrícola Municipal 2019. Instituto Brasileiro de Geografia e Estatística, 2020a. Disponível em: https://sidra.ibge.gov.br/pesquisa/pam/tabelas. Acesso em: 21 mai. 2021.

IBGE. Produção da Extração Vegetal e da Silvicultura 2019. Instituto Brasileiro de Geografia e Estatística, 2020b. Disponível em: https://sidra.ibge.gov.br/pesquisa/pevs/quadros/brasil/2018. Acesso em: 21 mai. 2021.

LEITE, Alexandre César Cunha; PICCHI, Lívia. Os impactos socioambientais resultantes da implantação e operação dos parques eólicos no estado da Paraíba. Revista de Pesquisa em Políticas Públicas, n. 1, p. 01-27, 2019. DOI: 10.18829/1805. 
LIMA, Lucas Gama; BARBOSA, Jéssica L.; SANTOS, José Rodolfo; LIMA, Eduardo N. O deserto verde cresce em Alagoas: uma análise crítica da expansão do eucalipto no estado. Caderno de Geografia, v. 30, n. 63, p. 1210-1229, 2020.

MACHADO, Lia Osório. O controle do território amazônico. Revista Território, v. 2, n. 1, p. 1932, 1997.

MAM. Mineração em Caetité- Bahia: contradições de uma tragédia anunciada. Movimento pela Soberania Popular na Mineração, publicado em 27 jul. 2018. Disponível em: https://mamnacional.org.br/2018/07/27/mineracao-em-caetite-bahia-contradicoes-de-uma-tragediaanunciada/. Acesso em: 21 mai. 2021.

MARTINS, José de Souza. Camponeses e Política no Brasil. Petrópolis: Editora Vozes, 1995.

MARX, Karl. O Capital. A crítica da economia política. Livro III - O processo global da produção capitalista. São Paulo: Boitempo, 2017.

McKAY, Ben. The politics of control: new dynamics of agrarian change in Bolivia's soy complex, 2017, 290 f. Thesis (PhD in Agrarian Studies) - International Institute of Social Studies, Erasmus University Rotterdam, The Hague, 2017

MOREIRA, Emilia de Rodat; TARGINO, Ivan. Capítulos de Geografia Agrária da Paraíba. João Pessoa: Editora Universitária, 1996.

MOREIRA, Emilia de Rodat Fernandes; BONOLO, Flávia; TARGINO, Ivan. Estrangeirização das terras: algumas notas sobre o caso do Brasil e da Paraíba. VINHA, Janaina Francisca de Souza Campos; COCA, Estevan Leopoldo de Freitas; FERNANDES, Bernardo Mançano (Org.). DATALUTA: questão agrária e coletivo de pensamento, 2014, p. 235-248.

MOREIRA, Ruy. Sociedade e espaço no Brasil (as fases da formação espacial brasileira: hegemonias e conflitos). Boletim Paulista de Geografia - Associação dos Geógrafos Brasileiros - São Paulo, n. 83, p. 07-31, 2005.

MOREIRA, Ruy. Mudar para manter exatamente igual. Os ciclos espaciais de acumulação. O espaço total. Formação do espaço agrário. São Paulo: Consequência, 2018.

MOREIRA, Ruy. Sociedade e espaço geográfico no Brasil - constituição e problemas de relação. São Paulo: Editora Contexto, 2019.

MOREIRA, Ruy. A formação espacial brasileira: contribuição crítica aos fundamentos espaciais da geografia do Brasil. Rio de Janeiro: Consequência, 2020.

NOVA CANA. Biosev vende Usina Giasa ao Grupo Olho D’Água por R\$ 70 milhões. Nova Cana, caderno Usinas, publicado em 12 nov. 2018. Disponível em: https://www.novacana.com/n/industria/usinas/biosev-vende-usina-giasa-grupo-olho-d-agua-r-70milhoes-121118. Acesso em: 22 mai. 2021.

OLIVEIRA, Ariovaldo Umbelino de. Integrar para não entregar: Políticas Públicas e Amazônia. Campinas: Papirus, 1988.

OLIVEIRA, Ariovaldo Umbelino de. Modo capitalista de produção, agricultura e reforma agrária. São Paulo: FFLCH, 2007.

OLIVEIRA, Nelma Gusmão de; BRITO, Diego Henrique Santos. Conflito ambiental no sertão baiano: o projeto Pedra de Ferro em Caetité e Pindaí. Rev. Bras. Estud. Urbanos Reg., v. 22, p. 01-29, 2020. 
OYA, Carlos. Methodological reflections on "land grab" databases and the "land grab" literature "rush". The Journal of Peasant Studies, v. 40, n. 3, p. 503-520, 2013.

PEREIRA, Lorena Izá. O jeitinho estrangeiro: as estratégias do capital internacional para o controle do território no Brasil. Revista Pegada, v. 19, n. 1, p. 162-181, 2018.

PEREIRA, Lorena Izá; PAULI, Lucas. MATOPIBA: controle do território e expansão da fronteira da estrangeirização da terra. Revista NERA, v. 22, n. 47, p. 148-172, dossiê MATOPIBA, 2019.

PRADO JR., Caio. Formação do Brasil contempôraneo (Colônia). São Paulo: Companhia das Letras, 2011.

REYES, Julie de los; SANWELL, Katie. Flex crops: a primer. Amsterdam: Transnational Institute, 2018.

SNCR. Sistema Nacional de Cadastro Rural. Instituto Nacional de Colonização e Reforma Agrária (INCRA). Disponível em: http://www.cadastrorural.gov.br/estatisticas/sncr-sistema-nacional-decadastro-rural. Acesso em: 16 nov. 2019.

SASSEN, Saskia. Expulsões. Brutalidade e complexidade na economia global. Rio de Janeiro/São Paulo: Paz \&Terra, 2016.

SAUER, Sérgio; LEITE, Acácio Z.; TUBINO, Nilton Luís G. Agenda política da terra no governo Bolsonaro. Revista da ANPEGE, v. 16, n. 29, p. 285-318, 2020.

SOUSA, Eliane F. M. de; OLIVEIRA, Nádja Melo de.; MOREIRA, Emilia de Rodat Fernandes. Exploração mineral, estrangeirização, ambiente e trabalho. Congresso Brasileiro de Geógrafos, Associação dos Geógrafos Brasileiros, Vitória, 10-16 de agosto de 2014. In: Anais..., Vitória: AGB, 2014.

SOUSA, Rafaela Lopes de; CAVALCANTE, Leandro V.; LIMA, Lucas C.; SANTOS, Camila D. dos. Quixeré/CE no olho do furacão do agronegócio: a injustiça socioambiental em análise. Revista Pegada, v. 20, n. 3, p. 62-83, 2019.

SOYER, Gabriel de Azevedo; BARBORSA JR., Ricardo. Estrangeirização de terras nas Relações Internacionais do Brasil. Contextualizaciones Latinoamericanas, año 10, n. 18, p. 01-16, 2018.

SVAMPA, Maristella. As fronteiras do neoextrativismo na América Latina. Conflitos socioambientais, giro ecoterritorial e novas dependências. São Paulo: Elefante, 2019.

TRALDI, Mariana. Acumulação por despossessão: a privatização dos ventos para a produção de energia eólica no semiárido brasileiro. Campinas, 2019. 378f. Tese (Doutorado em Geografia) Instituto de Geociências, Universidade Estadual de Campinas, Campinas, 2019.

VALOR ECONÔMICO. Tasnee vende controle da Cristal Pigamentos à Tronox por US\$1,67 bi. Valor Econômico, caderno Empresas, publicado em 21 fev. 2017. Disponível em: https://valor.globo.com/empresas/noticia/2017/02/21/tasnee-vende-controle-da-cristal-pigmentos-atronox-por-us-167-bi.ghtml. Acesso em: 22 mai. 2021. 